Canadian

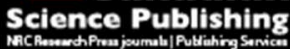

Canadian Journal of Microbiology Revue canadienne de de microbiologie

\title{
Evaluation of the pathogenic potential, antimicrobial susceptibility and genomic relations of Yersinia enterocolitica strains from food and human origin
}

\begin{tabular}{|r|l|}
\hline Journal: & Canadian Journal of Microbiology \\
\hline Manuscript ID & cjm-2015-0391.R1 \\
\hline Manuscript Type: & Article \\
\hline Date Submitted by the Author: & 10 -Aug-2015 \\
\hline Complete List of Authors: & $\begin{array}{l}\text { Lucero-Estrada, Cecilia Stella Msrys; Universidad Nacional de San Luis, } \\
\text { Área Microbiología; Instituto Multidisciplinario de Investigaciones } \\
\text { Biológicas-CONICET, Microbiología } \\
\text { Soria, Jose Miguel; Universidad Nacional de San Luis, Facultad de Química, } \\
\text { Bioquímica y Farmacia, Área Microbiología } \\
\text { Favier, Gabriela Isabel; Universidad Nacional de San Luis, Facultad de } \\
\text { Química, Bioquímica y Farmacia, Área Microbiología } \\
\text { Escudero, María Esther; Universidad Nacional de San Luis, Facultad de } \\
\text { Química, Bioquímica y Farmacia, Área Microbiología }\end{array}$ \\
\hline Keyword: & $\begin{array}{l}<\text { i>Yersinia enterocolitica</i>, food, human samples, pathogenic potential, } \\
\text { PFGE }\end{array}$ \\
\hline \multicolumn{2}{|c}{} \\
\hline
\end{tabular}


1 Evaluation of the pathogenic potential, antimicrobial susceptibility and genomic relations of

2 Yersinia enterocolitica strains from food and human origin.

3

4 Cecilia S.M. Lucero-Estrada ${ }^{1,2}$, José Miguel Soria ${ }^{1}$, Gabriela Isabel Favier ${ }^{1}$, María Esther

5 Escudero ${ }^{1}$.

$6{ }^{1}$ Microbiología General, Facultad de Química, Bioquímica y Farmacia, Universidad Nacional de

7 San Luis, Ejército de los Andes 950, Bloque 1, $1^{\circ}$ Piso, 5700, San Luis, Argentina

$8{ }^{2}$ Instituto Multidisciplinario de Investigaciones Biológicas, San Luis- Consejo Nacional de

9 Investigaciones Científicas y Tecnológicas (IMIBIO-CONICET), Ejército de los Andes 950,

10 Bloque $1,1^{\circ}$ Piso, 5700, San Luis, Argentina

13 Corresponding author: Cecilia S. M. Lucero: Microbiology General, Faculty of Chemistry,

14 Biochemistry and Pharmacy, National University of San Luis, Instituto Multidisciplinario de

15 Investigaciones Biológicas, San Luis- Consejo Nacional de Investigaciones Científicas y

16 Tecnológicas (IMIBIO-CONICET). Ejército de los Andes 950, Bloque 1, Piso 1, 5700, San Luis,

17 Argentina. Tel.: +54 2664520300 Int 1611, fax: + 542664431301.

18 E-mail address: cluceroestrada@gmail.com 
20

21

22 Yersinia enterocolitica is a foodborne pathogen that causes gastroenteritis with occasional post-

23 infection sequels. This study was aimed to determinate the pathogenic potential, antimicrobial

24 susceptibility and genomic relationships of $Y$. enterocolitica strains of different bioserotypes

$25(\mathrm{~B} / \mathrm{O})$ isolated from foods and human samples in San Luis, Argentina. Strains obtained by culture

26 were bioserotyped and characterized by phenotypic and genotypic virulence markers,

27 antimicrobial susceptibility, and PFGE. Y. enterocolitica was detected in $9.2 \%$ out of 380

28 samples with a distribution of $10.6 \%(30 / 284)$ for food products and 5.2\% (5/96) for human

29 samples. Regarding the pathogenic potential, B1A strains of different serotypes were virF ail ${ }^{-}$,

30 being $72.0 \%(13 / 18)$ of them $y s t B^{+}$with virulence-related phenotypic characteristics. Among

31 B2/O:9 isolates, 75.0\% (9/12) exhibited the genotype $v i r F^{+}$ail ${ }^{+} y s t B^{-}$along with phenotypic traits

32 associated to virulence; the same genotype was observed in 80.0\% (4/5) of B3/O:3 and B3/O:5

33 strains. By PFGE, it was possible to separate $Y$. enterocolitica biotypes into four clonal groups (A

34 to D) with 23 genomic types, generating a discriminatory index of 0.96 . All isolates were

35 susceptible to antimicrobials used for clinical treatment. This study highlights the presence of

36 pathogenic bioserotypes and the high genomic diversity of the $Y$. enterocolitica strains isolated in

37 our region.

38

39

40 Keywords:

41 Yersinia enterocolitica; foods; human samples; pathogenic potential; PFGE 


\section{Introduction}

$43 \quad$ Yersinia enterocolitica is a human foodborne enteropathogen that causes a self-limiting

44 gastroenteritis, extraintestinal manifestations and postinfectious sequelae such as erythema

45 nodosum and reactive arthritis (Bottone 1999). Pigs are regarded as major reservoirs of $Y$.

46 enterocolitica, and the most common route of transmission of yersiniosis is through raw or

47 inadequately cooked foods. The psychrotrophic nature of this bacterium is responsible of its

48 survival in household refrigerators (Bottone, 1999). This species includes a heterogeneous group

49 of strains, which are classified into six biotypes (B) and more than 57 serotypes $(\mathrm{O})$. Five of the

50 six biotypes (1B and 2-5) carry the $72 \mathrm{~kb}$ virulence plasmid (pYV) and several virulence

51 chromosomal genes, and are considered pathogenic to humans and animals (Fàbrega and Vila

52 2012). Instead, the B1A strains are generally regarded as avirulent as they lack the pYV plasmid

53 and major chromosomal virulence genes. Despite this, some B1A strains produce disease

54 symptoms indistinguishable from that caused by known pathogenic biotypes (Bhagat and Virdi

55 2011).

In Argentina, few studies have been performed to establish the role of this bacterium as a

57 causative agent of human disease, or to estimate its impact on foods intended for human

58 consumption. Y. enterocolitica B1A isolates have been reported from chicken carcasses in

59 Buenos Aires (Floccari et al. 2000) and recently, a Y. enterocolitica surveillance on meat foods

60 was carried out in Neuquén with positive results (Gottardi et al. 2012). In relation to human

61 samples, Eiguer et al. (1987) isolated one Y. enterocolitica B1A/O:5 strain from an asymptomatic

62 patient and another B4/O:3 strain from a child's diarrheic feces. More recently, Paz et al. (2004)

63 reported the isolation of one $Y$. enterocolitica B1A/O:5 strain from a diarrheic patient, and Cortes

64 et al. (2010) isolated six Y. enterocolitica strains from the diarrheic feces of six children out of 
65181 patients. In San Luis city, Y. enterocolitica B2/0:9 strains among other bioserotypes have

66 been isolated from different foods of animal origin, such as porcine, bovine, chicken meat, and

67 eggshells; however, they were not associated with food-borne outbreaks (Favier et al. 2005;

68 Lucero Estrada et al. 2011). The presence of chromosomal and plasmid-encoded virulence

69 markers is related to the potential pathogenicity of $Y$. enterocolitica strains as have been

70 demonstrated by PCR in isolates from Argentina and Brazil (Lucero Estrada et al. 2012; Paixão

71 et al. 2013). Additionally, the subtyping of this pathogen by molecular methods is especially

72 valuable since it permits to establish genomic relations between clones. In this way, pulsed field

73 gel electrophoresis (PFGE) has been widely used to determine strain relatedness, confirm

74 outbreaks and identify the different sources of isolates (Fredriksson-Ahomaa et al. 2006).

75 For contributing to the characterization of $Y$. enterocolitica strains from foods and human

76 samples in San Luis, the aims of this study were: i) to determine the pathogenic potential of the

77 isolates by phenotypic and genotypic tests, ii) to test the antimicrobial susceptibility, and iii) to

78 establish relationships among the isolates by means of genomic DNA macrorestriction analysis

79 using PFGE.

80

$81 \quad$ Materials and methods

82

83 Bacterial strains

Y. enterocolitica W1024 B2/O:9, provided by Dr. G. Cornelis (Belgium); Y. enterocolitica

85 MCH 700 B4/O:3 and Y. enterocolitica 29C/43 B4/O:3, both provided by Dr. G. Kapperud

86 (Norway), were used as reference strains. Four Yersinia intermedia, two Yersinia frederiksenii,

87 one Salmonella Enteritidis and one Salmonella Typhimurium strains previously isolated in our 
laboratory, were used to test the specificity of the 16S rRNA gene PCR. All strains were maintained in Luria Bertani broth plus $20 \%(\mathrm{v} / \mathrm{v})$ glycerol and stored at $-20^{\circ} \mathrm{C}$. For subsequent studies, Yersinia and Salmonella strains were individually grown in $5 \mathrm{ml}$ of trypticase soy broth (TSB, Britania, Buenos Aires, Argentina) for 18 to $20 \mathrm{~h}$ at $22^{\circ} \mathrm{C}$ and $37^{\circ} \mathrm{C}$, respectively.

\section{Sample collection}

In the two-year period 2010-2012, a total of 380 samples divided into two groups, were investigated for the presence of $Y$. enterocolitica:

$i$-food samples: a total of 284 samples were purchased at random from seven retail stores and supermarkets located in San Luis city, Argentina. The studied samples were: eggshells $(n=72)$, pork sausages $(n=74)$, minced meat $(n=68)$, and chicken carcasses $(n=70)$. After purchase, each sample was transported in its original container under refrigeration and immediately processed or stored at $4^{\circ} \mathrm{C}$ for up to $6 \mathrm{~h}$.

$i i$-clinical samples: 96 fecal samples from patients with diarrhea were collected from three public and private clinical laboratories located in San Luis city, Argentina The samples were from patients under 10 years old, negative for Salmonella spp, Shigella spp and Escherichia coli $\mathrm{O} 157 \mathrm{H}: 7$.

\section{Microbiological analysis}

Y. enterocolitica cultures from food samples were performed according to the FDA Bacteriological Analytical Manual (Weagant and Feng 2001). Samples of $25 \mathrm{~g}$ were homogenized in stomacher (IUL Masticator, Germany) for $30 \mathrm{~s}$ and incubated in $225 \mathrm{ml}$ peptone sorbitol bile broth (PSBB; Britania) at $10^{\circ} \mathrm{C}$ for 10 days. Eggshells were treated according to 
111 Favier et al. (2005) with some modifications; briefly, entire eggs were individually placed in 112 sterile plastic bags containing $25 \mathrm{ml}$ of TSB (Britania), softly hand shaken for 1 min to facilitate 113 bacterial detachment and incubated at $25^{\circ} \mathrm{C}$ during $24 \mathrm{~h}$. After that, one milliliter of TSB was 114 taken and diluted in $99 \mathrm{ml}$ of PSBB for incubation at $10^{\circ} \mathrm{C}$ for 9 days. Isolation from fecal 115 samples was performed according to HaoXuan et al. (2006) with some modifications. In brief, $1160.5 \mathrm{~g}$ of sample was added into $4.5 \mathrm{ml}$ of $0.85 \% \mathrm{NaCl}$. After homogenization, one ml was seeded 117 into $9 \mathrm{ml}$ of PSBB and cultured for 10 days at $10^{\circ} \mathrm{C}$. After enrichment period, $0.1 \mathrm{ml}$ of each 118 sample was spread on Mac Conkey (MC, Britania) and cefsulodin-irgasan-novobiocin (CIN, 119 Merck, Darmstadt, Germany) agars, and incubated for $48 \mathrm{~h}$ at $25^{\circ} \mathrm{C}$ and $37^{\circ} \mathrm{C}$, respectively. 120 Typical colonies were picked and tested by Gram staining and classical biochemical methods 121 (Bottone et al. 2005). Confirmation of biotypes and serotypes were performed by Dr. E. Carniel, 122 Reference Center for Yersinia, Pasteur Institute, Paris, France.

\section{Virulence phenotypic tests}

The following assays were performed as described previously: autoagglutination at $37^{\circ} \mathrm{C}$

126 (Laird and Cavanaugh 1980), calcium-dependent growth, and Congo red absorption (CR-MOX)

127 in order to differentiate between plasmid-bearing and plasmidless strains, esculin hydrolysis and 128 pyrazinamidase production to demonstrate other virulence traits (Farmer et al. 1992; Riley and 129 Toma 1989).

\section{Antimicrobial susceptibility}

The antimicrobial susceptibility of $Y$. enterocolitica isolates was determined by the disk

133 diffusion method on Mueller Hinton agar (MH; Britania, Buenos Aires, Argentina) performed 
134 according to the Clinical and Laboratory Standards Institute guidelines (CLSI 2014). The

135 following antibiotic disks (Britania) were used: amikacin $(30 \mu \mathrm{g})$, ampicillin $(10 \mu \mathrm{g})$, aztreonam

$136(30 \mu \mathrm{g})$, cephalothin $(30 \mu \mathrm{g})$, cefuroxime $(30 \mu \mathrm{g})$, ciprofloxacin $(5 \mu \mathrm{g})$, chloramphenicol $(30 \mu \mathrm{g})$, 137 colistin $(10 \mu \mathrm{g})$, erythromycin $(15 \mu \mathrm{g})$, phosphomycin $(50 \mu \mathrm{g})$, furazolidone $(5 \mu \mathrm{g})$, gentamicin

$138(10 \mu \mathrm{g})$, kanamycin $(30 \mu \mathrm{g})$, nalidixic acid $(30 \mu \mathrm{g})$, neomycin $(30 \mu \mathrm{g})$, rifampicin $(5 \mu \mathrm{g})$,

139 tetracycline $(30 \mu \mathrm{g})$ and trimethoprim-sulfamethoxazole $(25 \mu \mathrm{g}$, TMS). Zones of growth

140 inhibition were evaluated according to CLSI standards (2014). The reference strain Escherichia

141 coli ATCC 25922 was used as a control.

\section{DNA extraction}

DNA extraction was made using a boiling protocol with minor modifications (Leotta et al.

2005). Briefly, one milliliter of $Y$. enterocolitica suspension was centrifuged at 10,000 rpm for 5 min. The pellet was suspended in $150 \mu$ of TE1X buffer [10mM Tris (Sigma Aldrich, St. Louis, MO, USA), 1mM EDTA (Sigma), pH 8.0] added with 1\% Triton-X100 (Parafarm, Buenos Aires,

148 Argentina), boiled for $15 \mathrm{~min}$ and then, centrifuged at $10,000 \mathrm{rpm}$ for $5 \mathrm{~min}$. A $50 \mu \mathrm{l}$ aliquot of 149 the supernatant containing DNA was transferred to other tube and stored at $4^{\circ} \mathrm{C}$.

Polymerase chain reaction for $16 \mathrm{~S}$ rRNA gene detection

A $25 \mu$ volume of a reaction mix containing $1 \mathrm{X}$ PCR buffer, $0.2 \mathrm{mM}$ dNTPs, $1.5 \mathrm{mM}$

$153 \mathrm{MgCl}_{2}, 1 \mathrm{pmol} / \mathrm{ml}$ of each specific primer (forward 5'- GGAATTTAGCAGAGATGCTTTAG -3'

154 and reverse 5'-GGACTACGACAGACTTTATGTG-3'), 1 U Taq polymerase (PB-L, Quilmes, 155 Argentina), $2 \mu 1$ template, and ultrapure water was prepared. The primers were designed in this 156 study using GenBank accession number NC_015475.1, and OligoCalc software (Kibbe 2007). 
157 PCR was performed as follows: $95^{\circ} \mathrm{C}$ for $5 \mathrm{~min}$, then 25 cycles of $95^{\circ} \mathrm{C}$ for $30 \mathrm{~s}, 54^{\circ} \mathrm{C}$ for $30 \mathrm{~s}$ 158 and $72^{\circ} \mathrm{C}$ for $30 \mathrm{~s}$, and a final extension of $72^{\circ} \mathrm{C}$ for $3 \mathrm{~min}$ in a thermocycler (BioRad, Hercules, 159 CA, USA). The products were analyzed by $2 \%$ agarose gel electrophoresis in comparison with a 160 100-bp molecular weight DNA marker (PB-L, Quilmes, Argentina). The bands were visualized 161 by staining with GelRed ${ }^{\circledR}$ Acid Gel Stain (Biotium, Hayward, CA, USA), $1.5 \mu$ l stock 162 solution/40 $\mathrm{ml}$ gel, and photographed.

\section{Multiplex PCR for virulence genetic markers}

Three virulence genetic markers, virF, ail and $y s t B$, were assayed by multiplex PCR with using primers presented in Table 1. A step-by-step empirical approach was used to determine the

167 optimal annealing temperature, raising the temperature from 55 to $60^{\circ} \mathrm{C}$ with $1{ }^{\circ} \mathrm{C}$ increments, and 168 the concentration of primers, $\mathrm{MgCl}_{2}$ and deoxynucleoside triphosphates in the reaction mixture. The final PCR protocol was as follows: 1x PCR buffer, $1.5 \mathrm{mM} \mathrm{MgCl}_{2}, 1 \mathrm{U}$ of Taq DNApolymerase, $0.2 \mathrm{mM}$ of each dNTP, $10 \mathrm{pmol}$ each primer set, and two $\mu 1$ of DNA as template.

171 The amplification conditions were: $95^{\circ} \mathrm{C}$ for $3 \mathrm{~min}$, followed by 25 cycles of $95^{\circ} \mathrm{C}$ for $45 \mathrm{~s}, 58^{\circ} \mathrm{C}$ 172 for $45 \mathrm{~s}$ and $72^{\circ} \mathrm{C}$ for $45 \mathrm{~s}$, with a final extension at $72^{\circ} \mathrm{C}$ for $5 \mathrm{~min}$. The products were analyzed 173 and visualized as described previously.

175 Pulsed-field gel electrophoresis (PFGE)

176 All strains were genotyped by PFGE according to the PulseNet protocol

177 (http://www.cdc.gov/pulsenet/PDF/ecoli-shigella-salmonella-pfge-protocol-508c.pdf) with some 178 modifications. Bacterial cells grown overnight on trypticase soy agar (TSA; Britania) plates were 179 suspended directly in $4 \mathrm{ml}$ of the suspension buffer (100 mM Tris, $100 \mathrm{mM}$ EDTA, pH 8.0) to 
$\mathrm{OD}_{610 \mathrm{~nm}}$ 1.0. Two hundred microliters of bacterial suspension were mixed with equal volume of 1\% SeaKem Gold agarose (Cambrex, Rockland, ME, USA) and poured in molds to obtain “plugs". Plugs were treated for $20 \mathrm{~h}$ in a lysis solution (50 mmol Tris-EDTA, Sigma; 1\% sodium

183 lauroyl sarcosine, Sigma; and Proteinase K $0.1 \mathrm{mg} / \mathrm{ml}$, Fluka Chemie, Buchs, Switzerland; pH $1848.0)$ at $37^{\circ} \mathrm{C}$ and then washed four times with TE buffer (10 mM Tris, Sigma; $1 \mathrm{mM}$ EDTA, Sigma; $\mathrm{pH} 8.0$ ) for $30 \mathrm{~min}$ at $37^{\circ} \mathrm{C}$. Chromosomal DNA contained in agarose plugs was digested with $10 \mathrm{U}$ XbaI (Fermentas, Burlington, Ontario, Canada) for two hours, according to manufacturer's instructions. Plugs were cut in approximately 1-mm-thick slices, placed in the CHEF-DRIII chamber (Bio-Rad, Hercules, CA, USA), and PFGE was performed using an electric, field of $6 \mathrm{~V} / \mathrm{cm}$ at $14^{\circ} \mathrm{C}$, angle of $120^{\circ}$ and switching times of $1.8-20 \mathrm{~s}$ over $20 \mathrm{~h}$. Migration of the DNA fragments was achieved in a $1.0 \%$ pulsed-field agarose gel (Bio-Rad) submerged in $0.5 \mathrm{x}$ TBE buffer (45 mmol/1 Tris-Borate and $1 \mathrm{mmol} / 1$ EDTA). Salmonella Braenderup H9812 strain was used a molecular reference marker. The gels were stained with Gel $193 \operatorname{Red}^{\circledR}$ Acid Gel Stain (Biotium) and photographed.

Statistical analysis of the frequency of $Y$. enterocolitica recovery related to the type of

197 sample was performed using Chi-square test (Analytical Software, Tallahassee FL, USA).

198 Calculations were based on confidence level equal or higher than $95 \%(\mathrm{p} \leq 0.05$ was considered statistically significant). The levels of relatedness of the isolates were determined through a

200 comprehensive pairwise comparison of restriction fragment sizes, using the Dice coefficient. The 201 discrimination index (DI) values of PFGE were calculated by Simpson's diversity index (Hunter 202 and Gaston 1998). Clustering of the patterns obtained by the PFGE was performed using 
203 Statistica 6.0 software (StatSoft Inc., Tulsa, OK, USA) and the mean values obtained from the 204 Dice coefficients were applied in the unweighted pair group method with arithmetic average 205 (UPGMA).

206

207 Results

208

209

Distribution of $Y$. enterocolitica in food and clinical samples

210

Results of distribution of $Y$. enterocolitica from food and clinical samples are summarized

211 in Table 2. A total of 35 (9.2\%) out of 380 samples were positive for Y. enterocolitica isolation.

212 Thirty strains were isolated from $10.5 \%$ food samples and five from $5.2 \%$ human feces being

213 B1A (18 strains) and B2 (12 strains) $(\mathrm{p} \leq 0.05)$ the most frequently isolated biotypes. Sixteen $Y$.

214 enterocolitica B1A strains were recovered from pork sausage, minced meat, chicken carcasses

215 (5.6\% of total food samples) and two from human feces (2.0\% of total fecal samples), while 11

$216 Y$. enterocolitica B2 strains were recovered from eggshell and one from pork sausage (4.2\% of

217 food). Moreover, two $Y$. enterocolitica B3 strains were recovered from pork sausage $(0.7 \%$ of

218 food) and another three strains from clinical samples (3.1\% of total fecal samples). The

219 frequency of isolation was significantly higher from eggshell (15.3\%) and minced meat (14.7\%)

220 than from the other food and human samples $(\mathrm{p} \leq 0.05)$.

221

222 Phenotypic and genotypic characterization of $Y$. enterocolitica isolates

223 All the strains isolated in this study including reference strains, amplified a 300 bp region 224 corresponding to $Y$. enterocolitica $16 \mathrm{~S}$ rRNA gene. Y. intermedia, Y. frederiksenii, S. Enteritidis 
225 and $S$. Typhimurium assayed to test the specificity of the $16 \mathrm{~S}$ rRNA gene PCR did not show this 226 band (Figure 1A and 1B).

The results of the phenotypic and genotypic virulence characteristics of $Y$. enterocolitica

228 strains are shown in Table 3. By multiplex PCR, most B2 $(75.0 \%, 9 / 12)$ and B3 $(80.0 \%, 4 / 5) Y$.

enterocolitica isolates presented the genotype $v i r F^{+}$ail ${ }^{+} y s t B^{-}$which was in agreement with the

230 virulence phenotype. Only four Y. enterocolitica, three B2 and one B3 isolates, showed the

231 genotype $\operatorname{virF}^{-}$ail $^{+} y s t B^{-}$(Figure 2A). All $Y$. enterocolitica $\mathrm{B} 1 \mathrm{~A}$ strains presented negative results

232 for phenotypic markers related to plasmid presence and positive results for hydrolysis of

233 pyrazinamide and aesculin. Although all B1A strains were negative for virF and ail genes, most

234 of them $(72.0 \%, 13 / 18)$ were positive for $y s t B$ gene (Figure $2 B)$.

236 Antimicrobial susceptibility

All the $Y$. enterocolitica strains isolated in this study were susceptible to amikacin,

238 aztreonam, cefuroxime, ciprofloxacin, chloramphenicol, colistin, phosphomycin, furazolidone,

239 gentamicin, kanamycin, nalidixic acid, neomycin, tetracycline and TMS, and resistant to

240 ampicillin, cephalothin, erythromycin and rifampicin (Table 4).

\section{PFGE}

Figure 3 shows the DNA restriction patterns and dendrogram obtained by this method.

244 Among the 38 studied strains, including 35 isolates obtained in this work plus three reference

245 strains, 23 different genomic types (GTs) were obtained, generating a DI of 0.958. Four major

246 clusters were generated: cluster A contained all Y. enterocolitica B1A strains grouped into 10

247 GTs $(\mathrm{DI}=0.908)$; cluster B included local and reference $Y$. enterocolitica $\mathrm{B} 2 / \mathrm{O}: 9$ strains 
248 separated into nine GTs $(\mathrm{DI}=0.923)$; cluster C involved only the reference $Y$. enterocolitica

249 B4/O:3 strains, and cluster D contained all Y. enterocolitica B3 strains separated into two GTs.

250 Seven GTs (30.5\%) included strains belonging to the same bioserotype (GTA5, GTA6, GTA7,

251 GTB1, GTB6, GTD1, GTD2) and the remaining 16 GTs (69.5\%) were composed by a unique

252 strain. GTA5 was the most common pattern band found, with six strains $(15.7 \%)$ included into

253 this group.

254 The Y. enterocolitica GFO017 B1A/O:7,8-8-8,19 strain isolated from human feces was

255 typed in GTA4, and shared 93\% of similarity with the GFO010 strain of the same bioserotype,

256 typed in GTA3, and isolated from food. GTA5 included the GFO044 B1A/O:5 strain isolated

257 from a human sample and five strains of the same bioserotype isolated from food samples. In

258 relation to B3/O:3 strains isolated from human samples, they typed together in GTD1 and had $25986 \%$ of similarity with B3/O:5 strains of food origin, included in GTD2.

260

261 Discussion

262 The presence of $Y$. enterocolitica on eggshells (Favier et al. 2005), poultry, pork, and beef

263 samples (Velázquez et al. 1993; Lucero Estrada et al. 2012; Favier et al. 2014) was previously

264 demonstrated in San Luis. These results encouraged further investigations in these kinds of

265 samples and the subsequent characterization of the isolated strains. In this study, thirty $Y$.

266 enterocolitica strains were recovered from 284 food samples after cold enrichment, which

267 represents a prevalence of $10.6 \%$. The biotype 1A combined with different serotypes (16 strains)

268 was the most frequently detected one, followed by B2/O:9 (12 strains) and B3/O:5 (two strains)

$269(\mathrm{p} \leq 0.05)$. These results showed a higher recovery rate than those previously obtained in our

270 laboratory; Velázquez et al. (1993) reported 1.1\% positive samples from 450 cold foods, which 
271 yielded four B2/O:9 and one B1A/O:5 strains, Favier et al. (2005) isolated 2.3\% of $Y$.

272 enterocolitica B2/O:9 from eggshell (8 strains), and Lucero Estrada et al. (2012) recovered 5.9\%

273 of B2/O:9 and B1A strains from meat products (14 strains). Bernardino-Varo et al. (2013)

274 published the isolation of B3 strains in $8.54 \%$ of raw cow's milk in Mexico City. Furthermore, 275 these authors isolated B1A strains in $70.0 \%$, B2 in $13.2 \%$, and B4 in $8.15 \%$ from their samples.

276 Current researches in Brazil indicate the recovery of $Y$. enterocolitica B4 and B1A from

277 slaughterhouses, markets and clinical cases in humans, by culture methods (Paixão et al. 2012;

278 2013). Even though none $Y$. enterocolitica B4/O:3 strain was isolated in the present study, foods 279 might probably act as vehicles for human infection by this bioserotype in Argentina (Eiguer et al. 280 1987).

Despite poultry seems no relevant in Y. enterocolitica transmission and eggshells and 282 chicken skin are uncommon foodstuffs, $91.6 \%$ of $Y$. enterocolitica $\mathrm{B} 2 / \mathrm{O}: 9$ strains were isolated 283 from eggshell and $11.1 \%$ of B1A strains from chicken carcasses in this work . Probably, the 284 contamination of these products could occur by contact with other $Y$. enterocolitica-contaminated 285 animal products on farms and transportation or handling in retail shops. When outer defense 286 barriers of eggshell such as the surface thin membrane of protein nature called cuticle are altered 287 or damaged, Y. enterocolitica might penetrate into the egg interior (Favier et al. 2009) and be 288 ingested by consumers through raw or unpasteurized egg-based meals. Outbreaks associated with 289 the consumption of $Y$. enterocolitica-contaminated eggs or poultry have not been reported 290 probably because any $Y$. enterocolitica remaining on eggshells (Favier et al. 2005) or chicken 291 carcasses is eliminated by washing or cooking. 
294 reported and all strains were isolated from sporadic cases. This is the first time that $Y$.

295 enterocolitica B3 has been isolated from human samples in our country but it was not possible to 296 correlate any human isolate with the probable source of transmission because we could not 297 analyze household samples or involved foods. To our knowledge, no Y. enterocolitica outbreak 298 related to human infection has been reported so far in Argentina. However, strains belonging to B1A/O:5 (Paz et al. 2004), B4 (Sanchez and Gonzalez 2013), and other bioserotypes (Cortes et al. 2010) have been sporadically recovered from human diarrheic feces in this country. Previously, the 16S rRNA gene has been used for the unambiguous identification of $Y$. enterocolitica within the genus by using PCR (Kechagia et al. 2007). Lantz et al. (1998) developed a pair of primers based on the variable V3 and V9 regions of this gene, which was also used for real time PCR amplification by Wolffs et al. (2004). As Y. intermedia strains were also detected with these primers (Lantz et al. 1998), we modified them by adding a guanine residue to the 3 ' extreme of both primers, and by substituting a cytosine by a guanine in the $20^{\text {th }}$ nucleotide of the reverse primer in order to increase its specificity. So, we demonstrated that these modified primers did not anneal to $16 \mathrm{~S}$ rRNA of related species and confirmed that all analyzed strains belonged to $Y$. enterocolitica.

We demonstrated the presumptive presence of the pYV virulence plasmid in the majority of the B2 and B3 strains of food and human origin which were positive for virF gene and 312 plasmid-related virulence phenotypic characteristics. However, since this gene was not amplified 313 in four strains belonging to these biotypes, we hypothesized that a mutation produced in virF 314 would not allow its amplification by PCR, or perhaps, the virulence plasmid was lost during the 315 bacterial isolation, storage, or enrichment procedures (Cornelis et al. 1998). These results were 316 consistent with a previous study conducted in our laboratory in which four of six Y. enterocolitica 
317 B2/O:9 and two B3/O:5 strains isolated from food samples showed pathogenicity potential in 318 virulence phenotypic tests and amplified virF, myf, ail and ystA genes; however, two B2/O:9 319 strains neither amplified virF gene nor showed pinpoint colonies on CR-MOX agar but exhibited 320 unspecific autoagglutination (Lucero Estrada et al. 2011).

The isolation of B1A strains from human samples with gastrointestinal symptoms (Bhagat 322 and Virdi 2011) and the detection of virulence markers by PCR (Campioni and Falcão 2014) still 323 intrigue many researchers on the pathogenic potential of these strains. In the present work, we 324 observed that although all B1A strains were negative for virF and ail genes by PCR in agreement 325 with the phenotypic assays, $72.0 \%$ were positive for $y s t B$ gene, including one isolated from 326 human feces. This gene has been previously described in Y. enterocolitica B1A strains isolated 327 from human samples, foods and other sources (Stephan et al. 2013; Wang et al. 2008). Also, a 328 study on 259 isolates of $Y$. enterocolitica and related species indicated that Yst-B might be the major contributor to diarrhea produced by this biotype (Singh and Virdi 2004). Besides, there is 330 evidence that infections with B1A strains are more common in individuals that are generally 331 predisposed to infections. So, the pathogenicity of this group might be mainly linked to an 332 attribute of the host that fails to resist the attack of a relatively innocuous agent (Bhagat and Virdi 333 2011).

Similarly to the present study, Favier et al. (2005) showed that all Y. enterocolitica strains 335 isolated from egg-surface were susceptible to amikacin, ciprofloxacin, chloramphenicol, and 336 TMS and resistant to rifampicin, while Lucero Estrada et al. (2012) observed that $Y$. 337 enterocolitica strains isolated from meat products were resistant to ampicillin, erythromycin and 338 cephalotin, in our region. The intrinsic resistance to $\beta$-lactam antibiotics by $Y$. enterocolitica is 339 well detailed in the literature (Bonke et al. 2011). Resistance to many $\beta$-lactam antibiotics and 
340 erythromycin in Y. enterocolitica strains isolated from foods in Italy (Bonardi et al. 2010) and

341 animal foods in Greece (Kechagia et al. 2007) has been detected. Human Y. enterocolitica strains

342 belonging to various bioserotypes in Switzerland showed similar antimicrobial susceptibility

343 results to those observed in this study (Fredriksson-Ahomaa et al. 2012).

344 To subtype $Y$. enterocolitica isolates and establish clonal relationships among them,

345 PFGE was performed; thus, it was possible to separate the analyzed isolates into four clonal

346 groups (A to D) based in their biotypes. Cluster A comprised the 18 Y. enterocolitica B1A strains

347 which were grouped into 10 GTs. Among these strains, two were isolated from human feces, one

348 clustered alone (GTA4) and the other one clustered together with five strains of the same

349 serotype (GTA5) isolated from food. Furthermore, the other strains isolated from foods were

350 separated according to their serotype but no clustering tendency among genomic types related to

351 source or any other identifiable determinant could be demonstrated. These results confirmed

352 earlier works where this biotype was highly diverse in terms of their genotypes; for instance in

353 San Luis City, Argentina, Lucero Estrada et al. (2011) performed XbaI-PFGE and observed that

35425 Y. enterocolitica B1A strains of diverse serotypes isolated from meat food were clustered in

35510 different genotypes. In Brazil, Paixao et al. (2013a) studied 22 B1A strains from pork, markets

356 and slaughterhouses by using NotI-PFGE, and also observed a higher heterogeneity since these

357 strains were grouped into 22 GTs. In this way, Wang et al. (2008) observed 31 GTs from 43 B1A

358 O:8 strains isolated from animals and foods in China, and Stephan et al. (2013) showed a great

359 genetic diversity among all B1A strains isolated from humans in Switzerland by performing

360 NotI-PFGE.

361 The cluster B included Y. enterocolitica B2/O:9 strains which showed the highest

362 genomic heterogeneity since 12 local strains produced eight GTs by PFGE and only two of these 
363 genotypes included more than one strain, even though all of them were recovered from eggshells. 364 The three virF B2/O:9 strains isolated from eggshell and pork sausage, clustered separately each 365 other and from the $\operatorname{vir} F^{+} \mathrm{B} 2 / \mathrm{O}: 9$ strains. This high genomic heterogeneity is consistent with 366 previous results (Lucero Estrada et al. 2012) and might be attributed to the different locations of 367 the food industries which delivered products to retail shops where samples were purchased, or to cross contamination during handling and transporting (Favier et al., 2005). Nevertheless, other

369 studies around the world have reported limited genetic diversity of B2/O:9 strains by this 370 technique. Thus, Okwori et al. (2009) in a PFGE analysis using NotI, ApaI and XhoI enzymes, 371 revealed five genotypes among 45 Y. enterocolitica $\mathrm{B} 2 / \mathrm{O}: 9$ strains isolated of human and non372 human samples; meanwhile, Wang et al. (2008) observed 16 PFGE patterns among 53 Chinese 373 isolates of $Y$. enterocolitica $\mathrm{B} 2 / \mathrm{O}: 9$.

The two reference B4/O:3 strains were grouped in cluster $\mathrm{C}$ separately of the local strains.

375 Lastly, the two clinical B3/O:3 strains of the present study shared 86\% similarity with B3/O:5

376 strains isolated from pork and were included in cluster D. Taking into account the close genomic 377 relationship between these B3 strains of different serotype and origin, the $100 \%$ similarity 378 observed among the four foodborne B1A strains and one clinical B1A strain in GT5 within 379 cluster A, and the lack of epidemiological data to relate each other, it is possible to suggest that in 380 these cases, sporadic isolations from diverse sources in a determined region during different 381 periods of time, could be linked to the spreading of a few Y. enterocolitica clones in the 382 environment, animal reservoirs, water or foods of that area. In conclusion, the results obtained in this study demonstrated the presence of several 384 pathogenic $Y$. enterocolitica strains in human clinical samples and various foodstuffs of our 385 region. The highest $Y$. enterocolitica recovery was observed in eggshell and minced meat being 
386 B1A in combination with different serotypes and B2/O:9 the predominant bioserotypes.

387 Furthermore, it was possible to show that all isolates were susceptible to antimicrobials used for 388 clinical treatment, and the presence of several phenotypic and genotypic virulence markers in 389 most of them. PFGE revealed heterogeneous DNA restriction patterns within each bioserotype 390 without discriminating by the source of isolation, and demonstrated the high genomic diversity of 391 the $Y$. enterocolitica strains isolated in our region. Regarding B1A strains, our results showed that 392 it is necessary to pursue further research on the true virulence potential of this biotype to be 393 considered as a rapidly emerging group within human pathogens. Y. enterocolitica isolation from 394 foods and clinical samples in our region emphasizes the need to continue the consumer's 395 education on proper food handling and cooking practices to decrease the risk of transmission of 396 this bacterium.

\section{Acknowledgements}

399 Authors wish to thank Dr. G. Orellano (San Luis, Argentina) for supplying E. coli ATCC strains 400 for antimicrobial susceptibility tests, and Dr. M. Pichel and N. Binztein for providing $S$.

401 Braenderup H9812 strain and Seakem agarose from National Institute of Infectious Diseases "Dr. 402 C. G. Malbrán”, Buenos Aires, Argentina. This work was supported by PROICO 2-0914, Science 403 and Technology Department, National University of San Luis, San Luis, Argentina.

405 References

406

407 Bhagat, N., and Virdi, J.S. 2011. The enigma of Yersinia enterocolitica biovar 1A. Crit. Rev. 408 Microbiol. 37(1): 25-39. doi: 10.3109/1040841X.2010.506429. PMID: 20883083 
410 Bernardino-Varo, L., Quiñones-Ramírez, E., Fernández, F.J., and Vázquez-Salinas, C. 2013.

411 Prevalence of Yersinia enterocolitica in raw cow's milk collected from stables of Mexico City. J.

412 Food Prot. 76(4): 694-698. doi: 10.4315/0362-028X.JFP-12-325.

413

414 Bonardi, S., Paris, A., Bassi, L., Salmi, F., Bacci, C., Riboldi, E., Boni, E., D'Incau,

415 M., Tagliabue, S., and Brindani, F. 2010. Detection, semiquantitative enumeration,

416 and antimicrobial susceptibility of Yersinia enterocolitica in pork and chicken meats in Italy. J.

417 Food Prot. 73(10): 1785- 1792. PMID: 21067665

418

419 Bonke, R., Wacheck, S., Stüber, E., Meyer, C., Märtlbauer, E. and, Fredriksson-Ahomaa, M., 420 2011. Antimicrobial susceptibility and distribution of $\beta$-lactamase A (blaA) and $\beta$-lactamase B 421 (blaB) genes in enteropathogenic Yersinia species. Microb. Drug Resist. 17(4): 575-581. doi: 422 10.1089/mdr.2011.0098. PMID: 21970627.

424 Bottone, E.J. 1999. Yersinia enterocolitica: overview and epidemiologic correlates. Microbes 425 Infect. 1(4): 323-333. PMID: 10602666.

427 Bottone, E.J., Bercovier, H., and Mollaret, H.H. 2005. Bergey’s Manual of Systematic 428 Bacteriology. Second Edition. Part B. The Proteobacteria. Yersinia 2, 838-848. New York, 429 EEUU: Editorial Springer. 
431 Campioni, F., and Falcão, J.P. 2014. Genotypic diversity and virulence markers of Yersinia 432 enterocolitica biotype 1A strains isolated from clinical and non-clinical origins. APMIS 122:

433 215-222. doi: 10.1139/cjm-2014-0211. PMID: 24869470.

434

435 CLSI. 2014. Performance Standards for Antimicrobial Susceptibility Testing: M100-S16.

436 Clinical and Laboratory Standards Institute.

437

438 Cornelis, G.R., Boland, A., Boyd, A.P., Geuijen, C., Iriarte, M., Neyt, C., Sory, M.P., and

439 Stainier, I. 1998. The virulence plasmid of Yersinia, an antihost genome. Microbiol. Mol. Biol.

440 Rev. 62(4): 1315-1352. PMID: 9841674.

441

442 Cortes, P.R., Contreras Funes, V., Huerta, V.G., and Dichiara, D.M. 2010. Yersinia enterocolitica

443 in the fecal material from 6 pediatric patients in the city of Córdoba. Rev. Argent. Microbiol.

$444 \quad$ 42(1): 79. doi: 10.1590/S0325-75412010000100015.

445

446 Eiguer, T., Mercado, E.C., Fronchkowsy, B., Foguelman, A., Fernandez, E., Marguet, R., 447 et al. 1987. Primer aislamiento y caracterización de Yersinia enterocolitica en heces humanas en 448 Argentina. Rev. Argent. Microbiol. 19(2): 71-76. PMID: 3503312.

450 Fàbrega, A., and Vila, J. 2012. Yersinia enterocolitica: pathogenesis, virulence and antimicrobial 451 resistance. Enferm. Infecc. Microbiol. Clin. 30(1): 24-32. doi: 10.1016/j.eimc.2011.07.017. 
453 Farmer III, J.J., Carter, G.P., Miller, V.L., Falkow, S., and Wachsmuth, I.K. 1992.

454 Pyrazinamidase, CRMOX agar, salicin fermentation-esculin hydrolysis, and d-xylose

455 fermentation for identifying pathogenic serotypes of Yersinia enterocolitica. J. Clin. Microbiol.

456 30(10): 2589-2594. PMID: 1400958.

457

458 Favier, G.I., Escudero, M.E., and de Guzmán, A.M. 2005. Genotypic and phenotypic

459 characteristics of Yersinia enterocolitica isolated from the surface of chicken eggshells obtained 460 in Argentina. J. Food Prot. 68(9): 1812-1815. PMID: 16161678.

461

462 Favier, G.I., Escudero, M.E., and de Guzmán, A.M. 2009. Inhibitory effects of sucrose fatty acid 463 esters on survival of Yersinia enterocolitica on eggshell surface and use of blue lake as indicator 464 of bacterial penetration into eggs. J. Appl. Microbiol. 106(3): 774-783. doi: 10.1111/j.1365465 2672.2008.04022.x. PMID: 19191962.

466

467 Favier, G.I., Lucero Estrada, C., Cortiñas, T., and Escudero, M.E. 2014. Detection and 468 characterization of Shiga toxin producing Escherichia coli, Salmonella spp and Yersinia strains 469 from human, animal and food samples in San Luis, Argentina. Int. J. Microbiol. 2014:284649. 470 doi: 10.1155/2014/284649. PMID: 25177351.

471

472 Floccari, M.E., Carranza, M.M., and Parada, J.L. 2000. Yersinia enterocolitica biogroup 1A 473 serotype O:5 in chicken carcasses. J. Food Prot. 63(11), 1591-1593. PMID: 11079706. 
475 Fredriksson-Ahomaa, M., Stolle, A., and Korkeala, H. 2006. Molecular epidemiology of Yersinia 476 enterocolitica infections. FEMS Immunol. Med. Microbiol. 47(3):315-329. PMID: 16872368.

477

478 Fredriksson-Ahomaa, M., Cernela, N., Hächler, H., and Stephan, R. 2012. Yersinia enterocolitica 479 strains associated with human infections in Switzerland 2001-2010. Eur. J. Clin. Microbiol.

480 Infect. Dis. 31(7):1543-1550. doi: 10.1007/s 10096-011-1476-7. PMID: 22071910. 481

482 Gottardi, G., Mazzeo, M., Navello, M., Sauer, H., Zitta, M., Muller, M., et al. 2012. Vigilancia de 483 Yersinia spp. en alimentos cárneos: experiencia en Neuquén (Abstract). XI Latin American 484 Congress of Microbiology and Food Hygiene, MICROAL 2012, Buenos Aires, Argentina. 485

486 Haoxuan, Z., Jide, W., Mingjun, Z., Yong, S., and Bo, J. 2006. Yersinia enterocolitica 487 identification in stool samples using real-time PCR. Diagn Microbiol Infect Dis. 488 doi:10.1016/j.diagmicrobio.2006.07.016. PMID:16989972. 489

490 Hussein, H.M., Fenwick, S.G., and Lumsden, J.S. 2001. A rapid and sensitive method for the 491 detection of Yersinia enterocolitica strains from clinical samples. Lett. Appl. Microbiol. 33(6): $492 \quad 445-449$.

493

494 Hunter, P., and Gaston, M.A. 1998. Numerical index of discriminatory ability of typing systems: 495 an application of Simpson's index of diversity. J. Clin. Microbiol. 35: 2826-2833. 
497 Kechagia, N., Nicolaou, C., Ioannidou, V., Kourti, E., Ioannidis, A., Legakis, N.J., et al. 2007.

498 Detection of chromosomal and plasmid encoded virulence determinants in Yersinia enterocolitica 499 and other Yersinia spp. isolated from food animals in Greece. Int. J. Food Microbiol. 118(3): 326500331.

501

502 Kibbe, W.A. 2007. OligoCalc: an online oligonucleotide properties calculator. Nucleic Acids 503 Research 35, 43-46.

504

505 Laird, W. J., and Cavanaugh, D. C. 1980. Correlation of autoagglutination and virulence of 506 Yersiniae. J. Clin. Microbiol. 11(4): 430-432. PMID: 7372804

507

508 Lantz, P.G., Knutsson, R., Blixt, Y., Al-Soud, W.A., Borch, E., and Rådström, P. 1998. Detection 509 of pathogenic Yersinia enterocolitica in enrichment media and pork by a multiplex PCR: a study 510 of sample preparation and PCR-inhibitory components. Int. J. Food Microbiol. 45(2): 93-105.

511 PMID: 9924940

512

513 Leotta, G.A., Chinen, I., Epszteyn, S., Miliwebsky, E., Melamed, I.C., Motter, M., et al. 2005.

514 Validation of a multiplex PCR for detection of Shiga toxin- producing Escherichia coli. Rev.

515 Argent. Microbiol. 37(1): 1-10. PMID: 15991473

516

517 Lucero Estrada, C.S. M., Velázquez, L. del C., Escudero, M.E., Favier, G.I, Lazarte, V., and de 518 Guzmán, A.M. 2011. Pulsed field, PCR ribotyping and multiplex PCR analysis of Yersinia 
519 enterocolitica strains isolated from meat food in San Luis Argentina. Food Microbiol. 28(1): 21520 28. doi: 10.1016/j.fm.2010.07.026. PMID: 21056771.

521

522 Lucero Estrada, C.S.M., Velázquez L. del C., Favier, G. I., Di Genaro, M.S., and Escudero, M.E. 523 2012. Detection of Yersinia spp. in meat products by enrichment culture, immunomagnetic 524 separation and nested PCR. Food Microbiol. 30(1): 157-163. doi: 10.1016/j.fm.2011.10.014.

525 PMID: 22265296

526

527 Okwori, A.E., Martínez, P.O., Fredriksson-Ahomaa, M., Agina, S.E., and Korkeala, H. 2009.

528 Pathogenic Yersinia enterocolitica 2/O:9 and Yersinia pseudotuberculosis 1/O:1 strains isolated 529 from human and non-human sources in the Plateau State of Nigeria. Food Microbiol. 26(8): 872$530 \quad$ 875. doi: 10.1016/j.fm.2009.06.001.

531

532 Paixão, R., de Gobbi, D.D., Raimundo, D.C., Hofer, E., Matte, M.H., and Moreno, A.M. 2012.

533 Characterization of Yersinia enterocolitica 4/O:3 isolated from slaughterhouses and pork in the 534 state of São Paulo, Brazil, and clinical cases in humans. Adv. Exp. Med. Biol. 954:117-122. doi: 535 10.1007/978-1-4614-3561-7_15. PMID: 22782754

536

537 Paixão, R., Moreno, L.Z., Sena de Gobbi, D.D., Raimundo, D.C., Hofer, E., Matté, M.H., et al. 538 2013. Characterization of Yersinia enterocolitica biotype 1A strains isolated from swine 539 slaughterhouses and markets Scientific World Journal. 2013:769097. doi: 10.1155/2013/769097. 540 PMID: 23476146. 
542 Paz, M., Muzio, H., Teves, S., and Santini, P. 2004. Analysis of a Yersinia enterocolitica isolated 543 from human diarrheic feces in Argentina. Rev. Argent. Microbiol. 36(4):164-169. PMID:

$544 \quad 15786868$.

545

546 Riley, G., and Toma, S. 1989. Detection of pathogenic Yersinia enterocolitica by using congo 547 red-magnesium oxalate agar medium. J. Clin. Microbiol. 27(1):213-214. PMID: 2913030.

549 Sanchez, M.L., and Gonzalez, L. L. 2013. Yersinia enterocolitica: prevalencia en niños con

550 diarrea atendidos en el Hospital Infantil Municipal de Córdoba durante 2010-2011.

551 (http://www.cobico.com.ar/wp-content/archivos/2013/02/PUBLICACION-DRA-SANCHEZ.pdf)

552

553 Singh, I., and Virdi, J. S. 2004. Production of Yersinia stable toxin (YST) and distribution of yst 554 genes in biotype 1A strains of Yersinia enterocolitica. J. Med. Microbiol. 53(11):1065-1068. 555 PMID: 15496381.

557 Stephan, R., Joutsen, S., Hofer, E., Säde, E., Björkroth, J., Ziegler, D., and Fredriksson-Ahomaa, 558 M. 2013. Characteristics of Yersinia enterocolitica biotype 1A strains isolated from patients and 559 asymptomatic carriers. Eur. J. Clin. Microbiol. Infect. Dis. 32(7):869-875. doi: 10.1007/s10096560 013-1820-1. PMID: 23354676.

561

562 Velázquez, L., Escudero, M.E., and Guzmán A.M.S. 1993. Biovars, serovars and phagovars of 563 Yersinia enterocolitica isolated from 450 samples of cold food in San Luis, Argentina. J. Food 564 Prot. 56(4): 333-335. 
566 Wang, X., Qiu, H., Jin, D., Cui, Z., Kan, B., Xiao, Y., Xu, Y., Xia, S., Wang, H., Yang, J., Wang,

567 X., Hu, W., Xu, J., and Jing, H. 2008. O:8 serotype Yersinia enterocolitica strains in China. Int. J.

568 Food Microbiol. 125(3): 259-266. doi: 10.1016/j.ijfoodmicro.2008.04.016. PMID:18541322.

569

570

571 Weagant, S.D., and Feng, P. 2001. Bacteriological Analytical Manual (BAM). Yersinia

572 enterocolitica. Chapter 8. Maryland, EEUU: Food and Drug Administration (FDA).

573

574 Wolffs, P., Knutsson, R., Norling, B., and Rådström, P. 2004. Rapid quantification of Yersinia

575 enterocolitica in pork samples by a novel sample preparation method, flotation, prior to real-time

576 PCR. J. Clin. Microbiol. 42(3): 1042-1047. PMID: 15004051.

577

578 Web references

579 htpp://www.cdc.gov/pulsenet/protocols/yersinia. Access April 2013.

580 
Figure captions

582

583

Figure 1: Simple PCR for detection of 16S rRNA gene in $Y$. enterocolitica. A) Lane 1: $Y$. intermedia B1/O:4,32-4,33; lane 2: Y. intermedia B1/O:52; lane 3: Y. intermedia B4/O:17; lane

4: Y. intermedia B4/O:40; lane 5: Y. frederiksenii no agglutinable; lane 6: standard size (100 bp to 1000 bp); lane 7: reference strain, Y. enterocolitica W1024; lane 8: negative control. lane 9: $Y$. frederiksenii O:16-16,29; lane 10: S. Enteritidis 9,12:g,m:-; lane 11: standard size (100 bp to 1000 bp); lane 12: S. Typhimurium 4,5,12:I:1,2. B) Lane 1: Y. enterocolitica W1024 B2/O:9; lane 2: Y. enterocolitica B2/O:9 (GFO041); lane 3: Y. enterocolitica B3/O:3 (GFO 045); lane 4: Y. enterocolitica B3/O:5 (GFO048); lane 5: Y. enterocolitica $\mathrm{MCH} 700$ B4/O:3; lane 6: Y. enterocolitica B1A/O:41,42-41,43 (GFO018); lane 7: negative control; lane 8: standard size (100 bp to $1000 \mathrm{bp})$.

Figure 2: Multiplex PCR targeting gene encoding virulence-associated properties from $Y$. W1024 B2/O:9; lane 2: Y. enterocolitica B2/O:9 (GFO041); lane 3: Y. enterocolitica MCH 700 B4/O:3; lane 4: standard size (100 bp to $1000 \mathrm{bp}$ ); lane 5: Y. enterocolitica B2/O:9 (GFA001); lane 6: Y. enterocolitica B3/O:5 (GFO048), lane 7: Y. enterocolitica B3/O:3 (GFO 045); lane 8: negative control. B) Lane 1: Y. enterocolitica B1A/O:7,8-8-8,19 (GFO022); lane 2: Y. enterocolitica B1A/O:41,42-41,43 (GFO018); lane 3: standard size (100 bp to $1000 \mathrm{bp}$ ); lane 4: 
603 (GFO012), lane 6: negative control; lane 7: Y. enterocolitica $\mathrm{MCH} 700 \mathrm{~B} 4 / \mathrm{O}: 3$ as a reference 604 strain.

605

606 Figure 3: PFGE patterns of 35 Y. enterocolitica isolates from food (30) and clinical (5)

607 samples. A) representative band patterns of each genotype (GT), and B) dendrogram. 

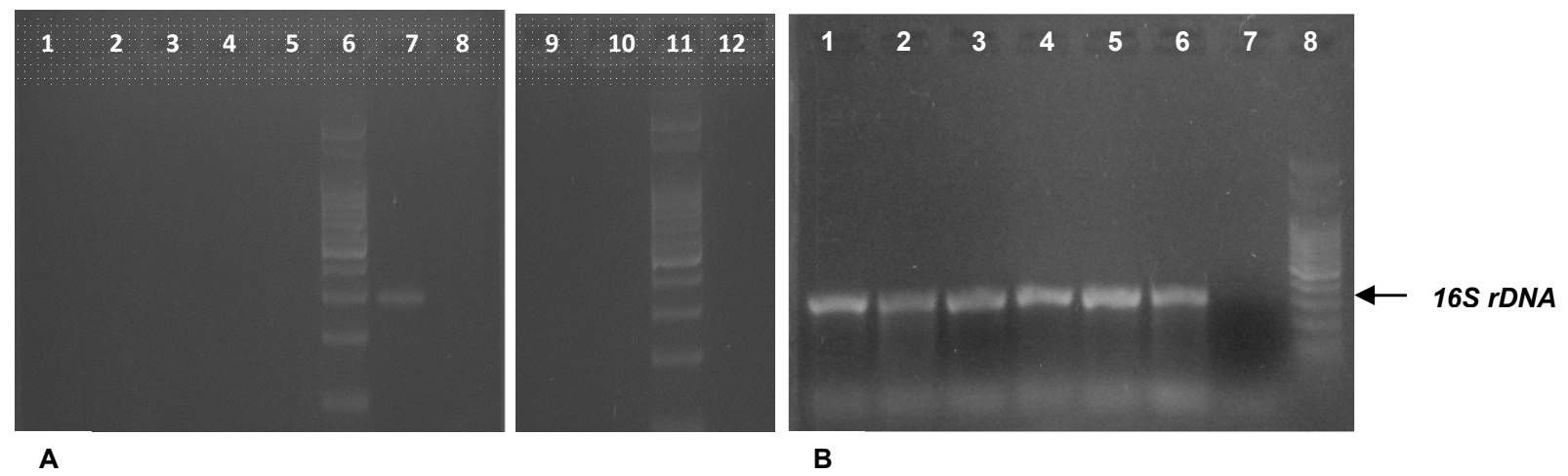

Figure 1 

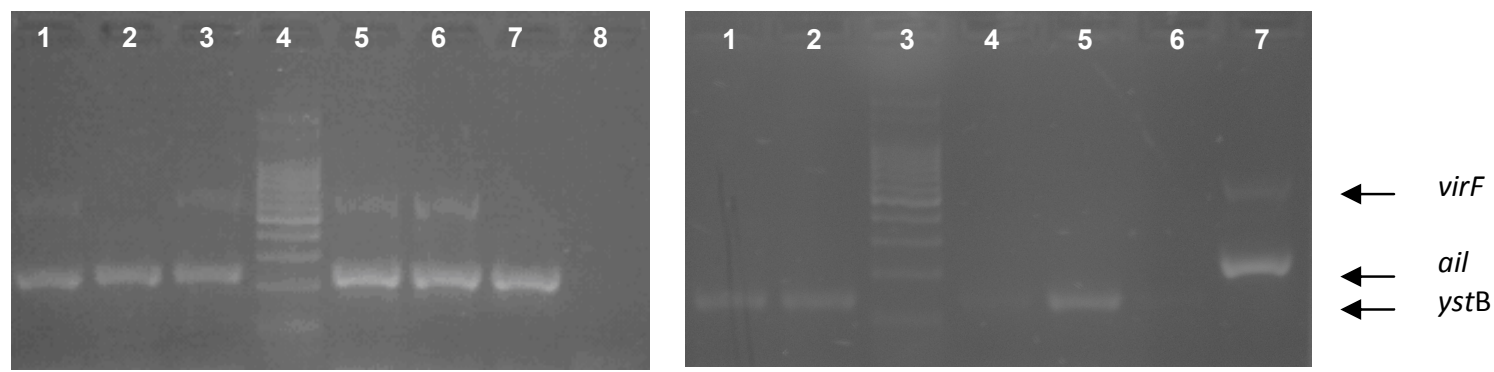

A

B

Figure 2 
A

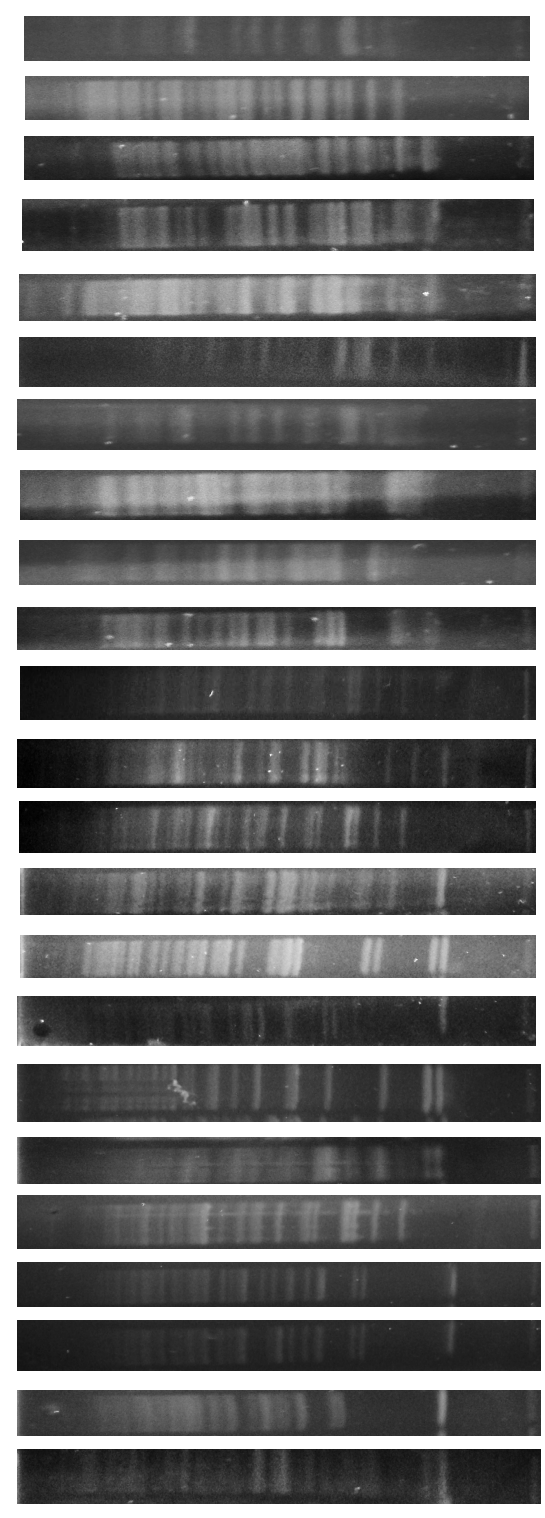

B
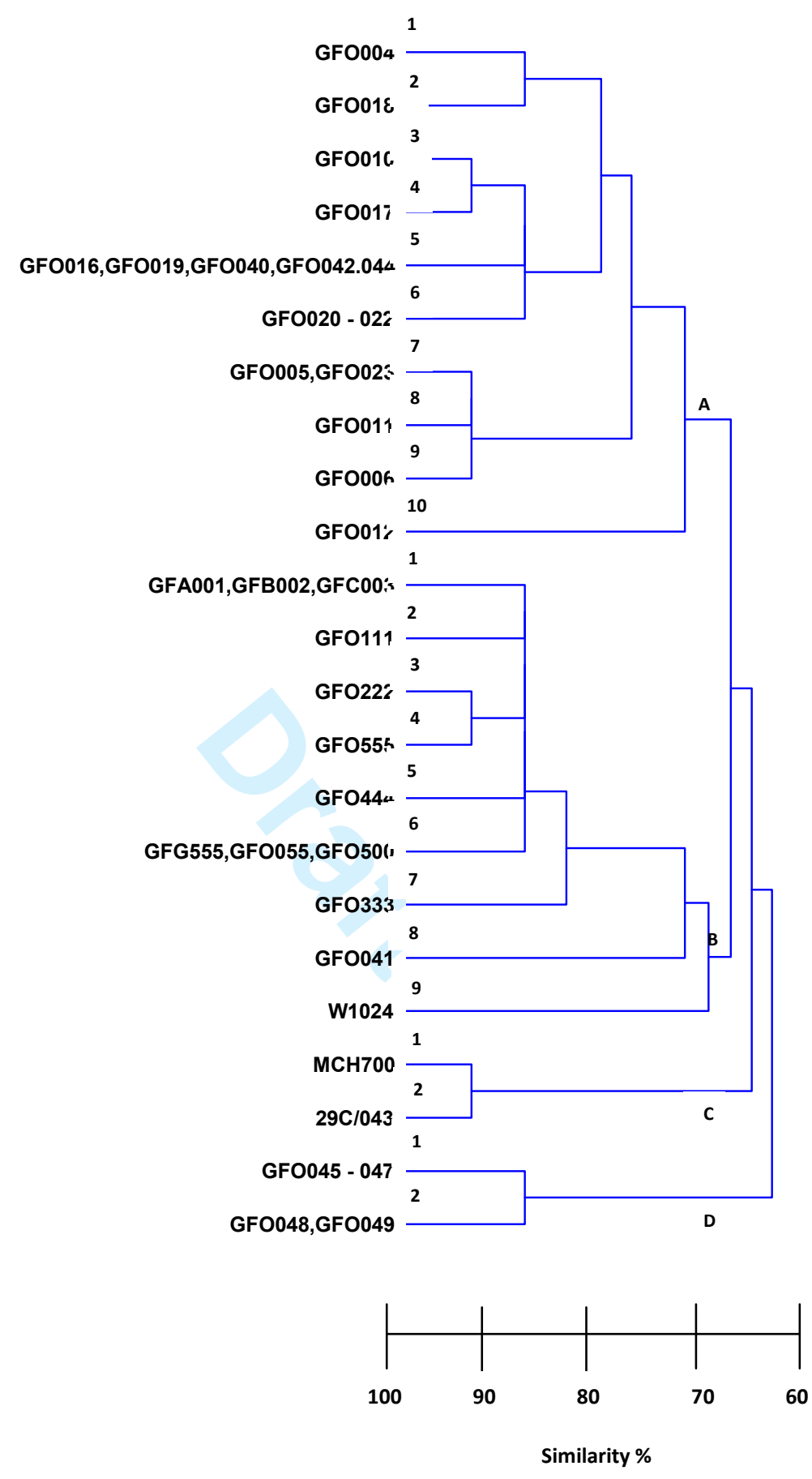

Figure 3. 
Table 1. Primers used for multiplex PCR and amplicon sizes

\begin{tabular}{llll}
\hline Gene & Sequence $\left(5^{\prime}{ }^{--} 3^{\prime}\right)$ & $\begin{array}{l}\text { Amplicon } \\
\text { length }(\mathrm{bp})\end{array}$ & Reference \\
\hline virF & $\begin{array}{l}\text { TCATGGCAGAACAGCAGTCAG } \\
\text { ACTCATCTTACCATTAAGAAG }\end{array}$ & 591 & Hussein et al., 2001. \\
ail & $\begin{array}{l}\text { GATGATAACTGGGGAGTAATAGG } \\
\text { CGTATGCCATTGACGTCTTAC }\end{array}$ & 238 & $\begin{array}{l}\text { This study } \\
\text { (GenBank accession } \\
\text { number M29945.1) }\end{array}$ \\
& & & Bhagat and Virdi, \\
$y s t$ B & $\begin{array}{l}\text { GTACATTAGGCCAAGAGACG } \\
\text { GCAACATACCTCACAACACC }\end{array}$ & 146 & 2007. \\
\hline
\end{tabular}


Table 2. Prevalence of Yersinia enterocolitica in food and clinical samples

\begin{tabular}{|c|c|c|c|c|}
\hline $\begin{array}{l}\text { Sample } \\
\text { type }\end{array}$ & Source & $\begin{array}{c}\mathrm{N}^{\mathrm{o}} \text { of } \\
\text { analyzed } \\
\text { samples }\end{array}$ & $\begin{array}{l}\mathrm{N}^{\mathrm{o}} \text { of positive } \\
\text { samples }(\%)\end{array}$ & $\begin{array}{l}\text { Y. enterocolitica } \\
\text { bio/serotype }\end{array}$ \\
\hline \multirow{4}{*}{$\begin{array}{l}\text { Food } \\
\text { samples }\end{array}$} & Eggshell & 72 & $11^{\mathrm{A}}(15.28)$ & 2/O:9 (11) \\
\hline & Pork sausage & 74 & $7^{\mathrm{B}}(9.46)$ & $\begin{array}{l}3 / \mathrm{O}: 5(2) \\
2 / \mathrm{O}: 9(1) \\
1 \mathrm{~A} / \mathrm{O}: 7,8-8-8,19(1) \\
1 \mathrm{~A} / \mathrm{O}: 4,32-4,33(1) \\
1 \mathrm{~A} / \mathrm{O}: 7,8-8-8-13-8,19(1) \\
1 \mathrm{~A} / \mathrm{O}: 5(1)\end{array}$ \\
\hline & Minced meat & 68 & $10^{\mathrm{A}}(14.70)$ & $\begin{array}{l}\text { 1A/O:5 (3) } \\
\text { 1A/O:1A O:7,8-8-8,19 (3) } \\
\text { 1A/O:4,32-4,33 (1) } \\
\text { 1A/O: 41,42-41,43 (1) } \\
\text { 1A/O:6,30-6,31(1) } \\
\text { 1A/NAG (1) }\end{array}$ \\
\hline & Chicken skin & 70 & $2^{\mathrm{D}}(2.86)$ & $\begin{array}{l}\text { 1A/O:5 (1) } \\
1 \mathrm{~A} / \mathrm{O}: 5-4,34-4,33(1)\end{array}$ \\
\hline $\begin{array}{l}\text { Clinical } \\
\text { samples }\end{array}$ & $\begin{array}{l}\text { Fecal } \\
\text { samples }\end{array}$ & 96 & $5^{\mathrm{C}}(5.21)$ & $\begin{array}{l}\text { 1A/O:7,8-8-8,19(1) } \\
1 \mathrm{~A} / \mathrm{O}: 5(1) \\
3 / \mathrm{O}: 3(3)\end{array}$ \\
\hline Total & & 380 & $35(9.21)$ & \\
\hline
\end{tabular}

\footnotetext{
${ }^{*}$ Values in the parenthesis indicate the number of strains belonging to each Y. enterocolitica bioserotype per type of sample.

NAG: non- agglutinable.

$\mathrm{A} ; \mathrm{B} ; \mathrm{C}$ Values followed by different capital letters indicate statistically significant differences $(\mathrm{p}<0.05)$.
} 
Table 3. Isolates and virulence markers detected using phenotypic tests and multiplex PCR

\begin{tabular}{|c|c|c|c|c|c|c|c|c|c|c|}
\hline \multirow{2}{*}{$\begin{array}{l}\text { Collection } \\
\text { Number }\end{array}$} & \multirow[t]{2}{*}{$\mathrm{B}^{*}$} & \multirow[t]{2}{*}{ Serotype $\dagger$} & \multirow[t]{2}{*}{ Origin } & \multicolumn{4}{|c|}{ Phenotypic characteristics } & \multicolumn{3}{|c|}{ Multiplex PCR: } \\
\hline & & & & $\overline{\mathrm{AA}}$ & $\mathrm{CR}$ & $\begin{array}{l}\text { Pyz } \\
\end{array}$ & Aes & $\operatorname{vir} \mathrm{F}$ & ail & ystB \\
\hline W 1024 & 2 & $0: 9$ & Reference & + & + & - & - & + & + & - \\
\hline МСH 700 & 4 & $0: 3$ & Reference & + & + & - & - & + & + & - \\
\hline $29 \mathrm{C} / 43$ & 4 & $\mathrm{O}: 3$ & Reference & + & + & - & - & + & + & - \\
\hline GFA001 & 2 & O:9 & egg & + & + & - & - & + & + & - \\
\hline GFB002 & 2 & O:9 & egg & + & + & - & - & + & + & - \\
\hline GFC003 & 2 & O:9 & egg & + & + & - & - & + & + & - \\
\hline GF0111 & 2 & O:9 & egg & + & + & - & - & - & + & - \\
\hline GFO222 & 2 & O:9 & egg & + & + & - & - & + & + & - \\
\hline GFO333 & 2 & O:9 & egg & + & + & - & - & + & + & - \\
\hline GFO444 & 2 & O:9 & egg & + & + & - & - & + & + & - \\
\hline GFO555 & 2 & O:9 & egg & + & + & - & - & - & + & - \\
\hline GFG555 & 2 & O:9 & egg & + & + & - & - & + & + & - \\
\hline GFO055 & 2 & O:9 & egg & + & + & - & - & + & + & - \\
\hline GFO500 & 2 & O:9 & egg & + & + & - & - & + & + & - \\
\hline GFO041 & 2 & O:9 & pork sausage & + & + & - & - & - & + & - \\
\hline GFO045 & 3 & $\mathrm{O}: 3$ & clinical sample & + & + & - & - & - & + & - \\
\hline GFO046 & 3 & $\mathrm{O}: 3$ & clinical sample & + & + & - & - & + & + & - \\
\hline GFO047 & 3 & $\mathrm{O}: 3$ & clinical sample & + & + & - & - & + & + & - \\
\hline GFO048 & 3 & O:5 & pork sausage & + & + & - & - & + & + & - \\
\hline GFO049 & 3 & O:5 & pork sausage & + & + & - & - & + & + & - \\
\hline GFO004 & $1 \mathrm{~A}$ & $7,8-8-8,19$ & pork sausage & - & - & + & + & - & - & + \\
\hline GFO005 & $1 \mathrm{~A}$ & $4,32-4,33$ & pork sausage & - & - & + & + & - & - & + \\
\hline GFO006 & $1 \mathrm{~A}$ & $6,30-6,31$ & minced meat & - & - & + & + & - & - & + \\
\hline GFO010 & $1 \mathrm{~A}$ & $7,8-8-13-8,19$ & pork sausage & - & - & + & + & - & - & + \\
\hline GFO011 & $1 \mathrm{~A}$ & NAG & minced meat & - & - & + & + & - & - & - \\
\hline GFO012 & $1 \mathrm{~A}$ & $5-4,34-4,33$ & chicken skin & - & - & + & + & - & - & + \\
\hline GFO016 & $1 \mathrm{~A}$ & 5 & minced meat & - & - & + & + & - & - & - \\
\hline GFO017 & $1 \mathrm{~A}$ & $7,8-8-8,19$ & clinical sample & - & - & + & + & - & - & + \\
\hline GFO018 & $1 \mathrm{~A}$ & $41,42-41,43$ & minced meat & - & - & + & + & - & - & + \\
\hline GFO019 & $1 \mathrm{~A}$ & 5 & minced meat & - & - & + & + & - & - & + \\
\hline GFO020 & $1 \mathrm{~A}$ & $7,8-8-8,19$ & minced meat & - & - & + & + & - & - & + \\
\hline GFO021 & $1 \mathrm{~A}$ & $7,8-8-8,19$ & minced meat & - & - & + & + & - & - & - \\
\hline GFO022 & $1 \mathrm{~A}$ & $7,8-8-8,19$ & minced meat & - & - & + & + & - & - & + \\
\hline GFO023 & $1 \mathrm{~A}$ & $4,32-4,33$ & minced meat & - & - & + & + & - & - & + \\
\hline GFO040 & $1 \mathrm{~A}$ & 5 & minced meat & - & - & + & + & - & - & + \\
\hline GFO042 & $1 \mathrm{~A}$ & 5 & chicken skin & - & - & + & + & - & - & - \\
\hline GFO043 & $1 \mathrm{~A}$ & 5 & pork sausage & - & - & + & + & - & - & + \\
\hline GFO044 & $1 \mathrm{~A}$ & 5 & clinical sample & - & - & + & + & - & - & - \\
\hline
\end{tabular}

* B: biotype.

$\dagger$ NAG: non-agglutinable.

$\$+/$, positive and negative reactions, respectively. AA: autoagglutination; CR: congo red absorption; Pyz:

pyrazynamidase reaction; Aes: aesculin hydrolysis. 
Table 4: Antimicrobial susceptibility of $Y$. enterocolitica strains isolated from food and human feces

\begin{tabular}{|c|c|c|c|c|c|c|c|c|c|c|c|c|c|c|c|c|c|c|c|}
\hline B & $\mathrm{N}^{\circ}$ & $\overline{\mathrm{AKN}}$ & $\mathrm{AM}$ & $\overline{\mathrm{AZT}}$ & CEF & CXM & CIP & CMP & $\mathrm{COL}$ & ERY & FOS & FUR & GEN & $\mathrm{K}$ & NAL & NEO & RFA & TET & SXT \\
\hline 2 & 15 & 100 & 0 & 100 & 0 & 100 & 100 & 100 & 100 & 0 & 100 & 100 & 100 & 100 & 100 & 100 & 0 & 100 & 100 \\
\hline 3 & 5 & 100 & 0 & 100 & 0 & 100 & 100 & 100 & 100 & 0 & 100 & 100 & 100 & 100 & 100 & 100 & 0 & 100 & 100 \\
\hline $1 \mathrm{~A}$ & 18 & 100 & 0 & 100 & 0 & 100 & 100 & 100 & 100 & 0 & 100 & 100 & 100 & 100 & 100 & 100 & 0 & 100 & 100 \\
\hline total & 38 & 100 & 0 & 100 & 0 & 100 & 100 & 100 & 100 & 0 & 100 & 100 & 100 & 100 & 100 & 100 & 0 & 100 & 100 \\
\hline
\end{tabular}

B: biotype, $\mathrm{N}^{\circ}$ : amount of strains

AKN (amikacin), AM (ampicillin), AZT (aztreonam), CEF (cephalothin), CXM (cefuroxime), CIP (ciprofloxacin), CMP (chloramphenicol), COL (colistin), ERY (erythromycin), FOS (phosphomycin), FUR (furazolidone), GEN (gentamicin), K (kanamicyn), NAL (nalidixic acid), NEO (neomycin), RFA(rifampicin), TET (tetracycline) and TMS (trimethoprim-sulfamethoxazole). 